\title{
Tobacco Use Cessation
}

National Cancer Institute

\section{Source}

National Cancer Institute. Tobacco Use Cessation. NCI Thesaurus. Code C96001.

Discontinuation of the use of tobacco in any form. 